\title{
Repair follows anatomy
}

\author{
Hans-Hinrich Sievers, MD
}

\footnotetext{
From the Department of Cardiac and Thoracic Vascular Surgery, University Medical Center Schleswig-Holstein, Campus Lübeck, Lübeck, Germany.

Disclosures: Author has nothing to disclose with regard to commercial support.

Received for publication March 16, 2018; accepted for publication March 20, 2018; available ahead of print April $14,2018$.

Address for reprints: Hans-Hinrich Sievers, MD, Department of Cardiac and Thoracic Vascular Surgery, University Medical Center Schleswig-Holstein, Ratzeburger Allee 160, Lübeck 23538, Germany (E-mail: Hans-Hinrich.Sievers@uksh.de).

J Thorac Cardiovasc Surg 2018;156:588-9

$0022-5223 / \$ 36.00$

Copyright $(2018$ by The American Association for Thoracic Surgery

https://doi.org/10.1016/j.jtcvs.2018.03.069
}

This is an exciting publication from the Brussel's Group on deep circumferential annuloplasty to improve repair of bicuspid aortic valves with a dilated annulus $(\geq 26 \mathrm{~mm})$ in 100 patients. $^{1}$ A total of 79 patients had prolapse of the anterior leaflet defined as the conjoined left and right cusps in type 1 left-right ${ }^{2}$ bicuspid aortic valve. The results were excellent with no in-hospital deaths and freedom from aortic regurgitation $\geq 2+$, and reoperation was $96.4 \%$ and $96.8 \%$ at 8 years postoperatively.

The aortic root anatomy of bicuspid valves is complex, partly depending on valve type. Annulus dilatation can occur in the septal area ranging from the maldeveloped commissure between the left and right coronary sinus to the nadir of the right coronary sinus. Often there is an indentation in the septum just beneath this commissure, aggravating annulus dilatation. By the way, is it possible that this septal myocardial disarrangement is involved in bicuspid valve development via induced pathological flow in the left ventricular outflow tract that may be related to leaflet separation? Especially, the external annulus (ventriculo-aortic junction) and the basal ring (annulus) of the right coronary sinus have different heights with respect to the sinotubular junction giving the appearance of a "sinking sinus",1,3 (Figure 1, $A)$. Any annuloplasty in general intends to approximate the nadirs of the sinuses in a dilated annulus to increase the coaptation of the leaflets and prevent further annulus dilatation, thereby stabilizing the repair. Conventional annuloplasty may not adequately prevent recurrence of annulus dilatation in this bicuspid valve annulus anatomy (Figure 1, B). Deep circumferential annuloplasty aims to correct the anatomic height difference of the "sinking sinus" by lowering the annuloplasty to the level of the annulus and additionally equalizes in part the malalignment of the noncoronary sinus that is often deeper in the left ventricular outflow tract typically for type 1 left-right bicuspid aortic valve with aortic insufficiency (Figure 1, C). ${ }^{4}$ The excellent results of this deep circumferential annuloplasty are apparent; however, the

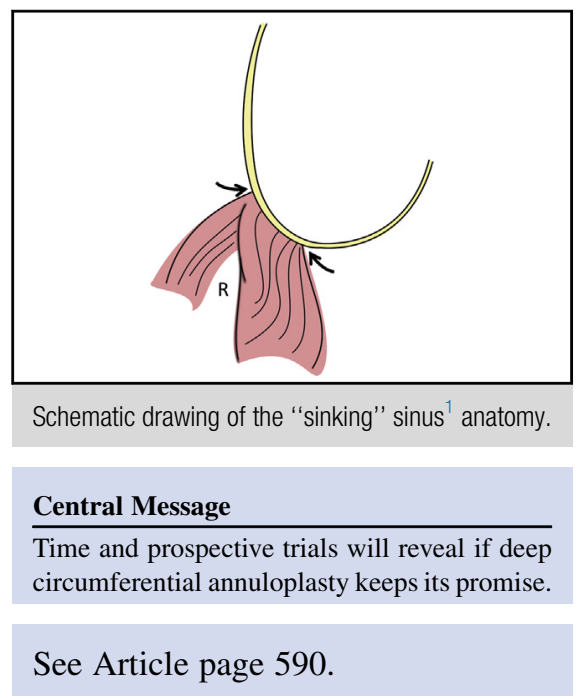

median follow-up was less than 3 years, and there are other reports of similar good results with partly less invasive techniques $^{5-8}$ (Figure $1, D$ ). Although this deep circumferential annuloplasty technique looks consequent, it is relatively invasive and has potential drawbacks such as possible rhythm disturbances, including pacemaker implantation, risk of the separation of the aortic root and septum that may impair root dynamics and ventriculo-aortic coupling, and breaching the right ventricular outflow tract.

The annulus is only 1 part of the bicuspid aortic valve repair procedure. Table 2 in the study by Nawaytou and colleagues $^{1}$ shows that several leaflet repair techniques were required, indicating that the leaflets are not normal in bicuspid aortic valves and long-term results also depend on leaflet quality and leaflet repair techniques. This is in contrast to most aortic root-sparing operations with tricuspid aortic valves. ${ }^{5}$ What is the reason for dilatation in the septal area in bicuspid aortic valves with aortic insufficiency? Is it a congenital abnormal architecture of the myocardial septal fibers or is it left ventricular dilatation due to long-standing aortic insufficiency? In the latter case, there is potential of reversal of annulus dilatation after successful repair bringing the remodeling technique into consideration, which seems to provide more physiologic root and leaflet dynamism. ${ }^{9}$ Time and prospective randomized trials will reveal if deep circumferential annuloplasty keeps its promise. 


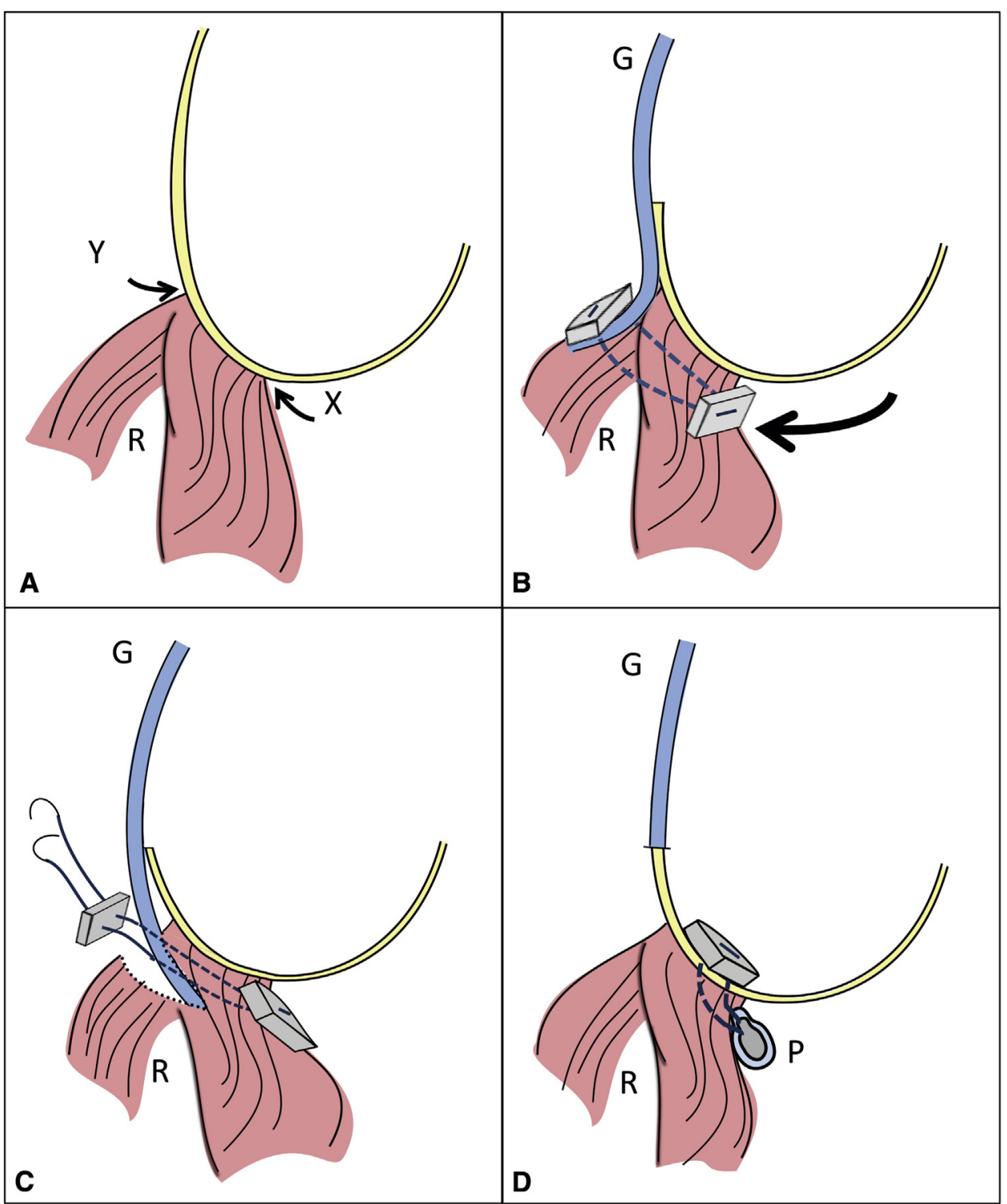

FIGURE 1. Schematic drawings of the "sinking" right coronary sinus and annuloplasty techniques. A, The "sinking" right coronary sinus ${ }^{1,3}$ results in different heights of the basal ring $(X)$ and the ventriculo-aortic junction $(Y)$ related to the sinotubular junction. B, Annuloplasty without muscle dissection may not adequately prevent recurrence of annulus dilatation (arrow). C, Deep circumferential annuloplasty ${ }^{1}$ lowers the annuloplasty toward the level of the annulus; note proximity to R. D, Internal ring annuloplasty with the fixation pledget in the sinus followed by the remodeling procedure. $R$, Right ventricular outflow tract; $G$, graft (blue line); $P$, prosthetic ring.

\section{References}

1. Nawaytou O, Mastrobuoni S, de Kerchove L, Baert J, Boodhwani M, El Khoury G. Deep circumferential annuloplasty as an adjunct to repair regurgitant bicuspid aortic valves with a dilated annulus. J Thorac Cardiovasc Surg. 2018;156:590-7.

2. Sievers HH, Schmidtke C. A classification system for the bicuspid aortic valve from 304 surgical specimens. J Thorac Cardiovasc Surg. 2007;133: 1226-33.

3. de Kerchove L, Jashari R, Boodhwani M, Duy KT, Lengele B, Gianello P, et al. Surgical anatomy of the aortic root: implication for valve-sparing reimplantation and aortic valve annuloplasty. J Thorac Cardiovasc Surg. 2015;149:425-33.

4. Sievers HH. Invited commentary. Ann Thorac Surg. 2009;87:82.

5. Klotz S, Stock S, Sievers HH, Diwoky M, Petersen M, Stierle U, et al. Survival and reoperation pattern after 20 years of experience with aortic valve-sparing root replacement in patients with tricuspid and bicuspid valves. J Thorac Cardiovasc Surg. 2018;155:1403-11.e1.

6. Schneider U, Hofmann C, Aicher D, Takahashi H, Miura Y, Schafers HJ. Suture annuloplasty significantly improves the durability of bicuspid aortic valve repair. Ann Thorac Surg. 2017;103:504-10.

7. Lansac E, Di Centa I, Sleilaty G, Lejeune S, Khelil N, Berrebi A, et al. Long-term results of external aortic ring annuloplasty for aortic valve repair. Eur J Cardiothorac Surg. 2016:50:350-60.

8. Scharfschwerdt M, Pawlik M, Sievers HH, Charitos EI. In vitro investigation of aortic valve annuloplasty using prosthetic ring devices. Eur J Cardiothorac Surg. 2011;40:1127-30.

9. Leyh RG, Schmidtke C, Bartels C, Sievers HH. Valve-sparing aortic root replacement (remodeling/reimplantation) in acute type A dissection. Ann Thorac Surg. $2000 ; 70: 21-4$. 